Short communication

\title{
Susceptibility testing of Candida albicans and Candida glabrata to Glycyrrhiza glabra L.
}

\author{
Natália Martins $^{\mathrm{a}, \mathrm{b}}$, Sofia Costa-Oliveira ${ }^{\mathrm{c}, \mathrm{d}}$, Luís D.R. Melo ${ }^{\mathrm{b}}$, Isabel C.F.R. Ferreira ${ }^{\mathrm{a}}$, \\ Joana Azeredo $^{\mathrm{b}}$, Mariana Henriques ${ }^{\mathrm{b}}$, Sónia Silva ${ }^{\mathrm{b}, *}$ \\ ${ }^{a}$ Mountain Research Centre (CIMO), ESA, Polytechnique Institute of Bragança, Campus de Santa Apolónia, 1172, $5301-855$ Bragança, Portugal \\ b CEB, Centre of Biological Engineering, LIBRO-Laboratório de Investigação em Biofilmes Rosário Oliveira, University of Minho, 4710-057 Braga, Portugal \\ c Department of Microbiology, Faculty of Medicine, Porto University, Alameda Professor Hernâni Monteiro, 4200-319 Porto, Portugal \\ d CINTESIS - Center for Health Technology and Services Research, Faculty of Medicine, University of Porto, Portugal
}

\section{A R T I C L E I N F O}

\section{Keywords:}

Glycyrrhiza glabra L.

Methanol: water extract

Anti-Candida activity

Mechanism of action

\begin{abstract}
A B S T R A C T
Medicinal plants and their botanical formulations have gained a pivotal attention among scientific researchers mainly due to its action as health promoters. Licorice (Glycyrrhiza glabra L.) constitutes a great example, with an increasingly evidenced antimicrobial potential. Opportunistic yeast infections constitute an alarming public health problem, highly exacerbated by the inefficacy of antifungal drugs and the increase of drug-resistant microorganisms, being Candida species one of the most common invaders. The present work aims to assess Candida glabrata and Candida albicans susceptibility to G. glabra methanol: water extract by using flow cytometry and transmission electron microscopy techniques. After $5 \mathrm{~min}$, licorice extract $(1.5 \mathrm{mg} / \mathrm{mL})$ altered Candida membrane potential. Within an hour, it induced primary damages on Candida species cells, causing cell cytoplasm disorganization with high evidence of cell membrane invaginations, making cells turgid. Thus, based on the current findings, licorice extract seems to be a promising anti-Candida agent, without presenting any toxic potential at the effective concentrations used.
\end{abstract}

\section{Introduction}

Medicinal plants have gained a special attention in the last years. In fact, natural matrices possess a multitude of health benefits (Faria et al., 2011; Lopes et al., 2013; Sher, 2009). Particularly, the study of the antifungal and anti-yeast properties against opportunistic fungi and yeasts, such as Candida species, is still being the focus of numerous researches (Martins et al., 2015b, 2014). Considered a commensal microorganism, being naturally present in gastrointestinal and genitourinary tracts of healthy population, Candida species have been increasingly associated with severe organic dysfunctions (Martins et al., 2014). As the fourth leading cause of systemic infections, they have markedly triggering the wellbeing involve in life-threatening situations (Martins et al., 2014).

Nowadays, there is a lack of antifungal agents with recognized efficiency, becoming urgent to provide a proper and efficient clinical intervention. Despite at several years ago these drugs exerted a potent effect, presently they are no longer effective (Martins et al., 2015b). In a general manner, microorganisms have shown increasing rates of drug resistance, and Candida species comprises a very good example (Martins et al., 2015b). Aiming to control/avert this emerging epidemic problem, numerous studies have been carried out to evaluate the acquired mechanisms of drug-resistance by Candida species, and to provide new insights to the candidiasis treatment (Jiang et al., 2014; Kanafani and Perfect, 2008; Perlin, 2009; Sanglard and Odds, 2002). However, besides the evaluation of an efficient multi-drug therapy, by using chemicals drugs or even natural products combination, the assessment of the corresponding mechanisms of action, the occurrence of morphological changes in Candida cells and the determination of kinetic parameters are also important. All these achievements will provide knowledge related with the type of cellular lesion occurred in Candida cells, to infer the relevance and interest of licorice extract for future applications, as also to analyze the feasibility to carry out more detailed studies, such as the assessment of in vitro and in vivo cytotoxic potential in human cells. Then, it will become possible to predict the in vivo safety and upcoming clinical use of the studied substances and the likelihood of side effects occurrence, both at short and middle-long terms.

Considering the previous results obtained to licorice extract (completely characterized in terms of phenolic composition), namely antioxidant (Martins et al., 2015a) and anti-Candida (Martins et al., 2016)

\footnotetext{
* Corresponding author.

E-mail address: soniasilva@deb.uminho.pt (S. Silva).
} 
activities, the present study aims to access the effect of licorice extract on cell integrity and cultivability of the most problematic and virulent Candida species, namely Candida albicans and Candida glabrata species (Martins et al., 2015c). The main aspects that triggered the development of this experiment was to understand in which manner licorice exerted its anti-Candida potential, once no visible effects were observed when isolated phenolic compounds present in the extract were tested separately, while with the whole extract a prominent effect was reached. Cell changes occurred after licorice application was assessed by flow cytometry and transmission electron microscopy.

\section{Material and methods}

\subsection{Plant material and phenolic extracts}

Glycyrrhiza glabra L. rhizomes and roots, supplied by Soria Natural (Garray - Soria, Spain), were obtained in autumn 2012, after reaching three years. Methanol: water extraction of licorice was performed by stirring the sample $(1 \mathrm{~g})$ with $30 \mathrm{~mL}$ of methanol/water $(80: 20, \mathrm{v} / \mathrm{v})$ at $25^{\circ} \mathrm{C}$ and $150 \mathrm{rpm}$ for $1 \mathrm{~h}$, and filtered through Whatman no. 4 paper. The obtained residue was again extracted with an additional $30 \mathrm{~mL}$ portion of the extraction solvents mixture. Then, combined extracts were evaporated at $35^{\circ} \mathrm{C}$ under reduced pressure (rotary evaporator Büchi R-210, Flawil, Switzerland) to remove the entire methanol used to perform phenolic extraction, and subsequently lyophilized (FreeZone 4.5, Labconco, Kansas City, MO, USA). Finally, the lyophilized extracts were re-dissolved in water, performing a stock solution with a concentration of $50 \mathrm{mg} / \mathrm{mL}$, from which several dilutions were prepared (Martins et al., 2015a).

The concentration tested in this study $(1.5 \mathrm{mg} / \mathrm{mL})$ was based on the obtained results for minimal inhibitory (MIC) and minimal fungicidal (MFC) concentrations (Martins et al., 2016), and prepared from a licorice stock solution of $50 \mathrm{mg} / \mathrm{mL}$. Sterile water was used as solvent.

\subsection{Standards and reagents}

Sabouraud Dextrose Broth (SDB) and Agar were from Merck (Darmstadt, Germany). Propidium iodide (PI) cell dye and HyClone Dulbecco's modified eagles medium (DMEM) were from Thermo Fisher Scientific (Wilmington, USA). Hank's balanced salt solution (HBSS), fetal bovine serum (FBS) and penicillin/streptomycin solution (100 U/ $\mathrm{mL}$ and $100 \mathrm{mg} / \mathrm{mL}$, respectively) were purchased from Gibco Invitrogen Life Technologies (California, USA). Water was treated in a Milli-Q water purification system (TGI Pure Water Systems, Greenville, SC, USA).

\subsection{Yeast strains}

In this study two different Candida species from the American Type Culture Collection (ATCC) were selected, namely Candida albicans ATCC 90028 and C. glabrata ATCC 2001 strains. The licorice extract concentration $(1.5 \mathrm{mg} / \mathrm{mL})$ was selected taking into consideration the previous results obtained (Martins et al., 2016) on the assessment of the anti-Candida activity in planktonic and their respective biofilms cells: $C$. albicans ATCC 90028 (MIC/MFC $\geq 1.5 \mathrm{mg} / \mathrm{mL}$ ), C. glabrata ATCC 2001 (MIC $=0.75 \mathrm{mg} / \mathrm{mL} ; \mathrm{MFC}=1.5 \mathrm{mg} / \mathrm{mL}$ ). Both strains were from the archive collection of the biofilm group of the Centre of Biological Engineering, University of Minho, Braga - Portugal.

\subsection{Assessment of licorice anti-Candida mechanism of action}

To perform the assessment of the effective mode of action of licorice extract on Candida species, a standard concentration of $1.5 \mathrm{mg} / \mathrm{mL}$ was used, based on the results obtained in the previous study (Martins et al., 2016).

\subsubsection{Cytometry experiments}

2.4.1.1. Staining procedures for flow cytometry experiments. The fluorescence probe PI was used to access the occurrence of cell membrane lesions in Candida species. Thus, two colonies from the sabouraud dextrose agar (SDA) were grown in SDB at $37^{\circ} \mathrm{C}, 150 \mathrm{rpm}$, until late exponential growth phase and collected by centrifugation ( $2655 \mathrm{~g}$, for $5 \mathrm{~min}$ ). Pellets were resuspended in water and the cell concentration adjusted to a final density of 0.5 McFarland, and then incubated with $1.5 \mathrm{mg} / \mathrm{mL}$ licorice methanol: water extract for 5,15 , 30 and $60 \mathrm{~min}$, without agitation, at $37^{\circ} \mathrm{C}$. After this time, Candida cells were collected by centrifugation, resuspended in water and stained with $1 \mu \mathrm{g} \mathrm{PI} / \mathrm{mL}$ in the dark, during $30 \mathrm{~min}$. Positive (i.e. cells treated with ethanol $90 \%$ ) and negative (i.e. cells without licorice methanol: water extract) controls were also included.

The staining cells were acquired in a FACSCalibur Cytometer (BD Biosciences, Sydney) standard model equipped with 3 photomultiplayers (PMTs), standard filters (FL1: BP 530/30 nm; FL2: BP 585/42 nm; FL3: LP $650 \mathrm{~nm}$ ) and a $15 \mathrm{~mW} 488 \mathrm{~nm}$ Argon Laser. Then, Candida cells were analyzed and the percentage of stained cells was determined, by using cell Quest Pro software (version 4.0.2, BD Biosciences, Sydney).

2.4.1.2. Assessment of kinetic curves. Parallel to flow cytometry approaches, kinetic growth studies were also performed, by cultivability assay methodology after treating Candida cells with licorice extract, for $5,15,30$ and $60 \mathrm{~min}$, at $37^{\circ} \mathrm{C}$. Thus, at predetermined time points, serial dilutions of yeasts suspensions were prepared and plated on SDA medium for colony-forming units (CFU) determination. Following incubation at $37^{\circ} \mathrm{C}$ for $24 \mathrm{~h}$, the number of $\mathrm{CFU}$ was determined and results presented as Log reduction (CFUs $/ \mathrm{mL}$ ) - Log reduction $=\log _{10}$ (number of viable cells before treatment) $\log _{10}$ (number of viable after treatment).

\subsubsection{Transmission electron microscopy (TEM)}

The effect of licorice extract on Candida cells morphological structure was observed by transmission electron microscopy (TEM). For that, Candida cells treated with $1.5 \mathrm{mg} / \mathrm{mL}$ of licorice extract during $30 \mathrm{~min}$, were prepared as described in previously section (2.4.1.1.) In brief, samples were fixed in $2.5 \%$ glutaraldehyde (Electron Microscopy sciences, Hatfield, USA) and 2\% paraformaldehyde (Merck, Darmstadt, Germany) in phosphate buffer $0.1 \mathrm{M}$ with $0.5 \mathrm{mM} \mathrm{MgCl}_{2}$ ( $\mathrm{pH}$ 6.5), dehydrated and embedded in Epon resin (TAAB, Berks, England). Ultrathin sections (40-60 nm thickness) were prepared on a RMC Ultramicrotome (PowerTome, USA) using diamond knives (DDK, Wilmington, DE, USA). The sections were mounted on 200 mesh copper or nickel grids, stained with uranyl acetate and lead citrate for 5 min each, and examined under a JEOL JEM 1400 TEM (Tokyo, Japan). Images were digitally recorded using a CCD digital camera Orious 1100W Tokyo, Japan at the HEMS/I3S from the University of Porto. ImageJ software (Rasband, 2017) was used to measure cell walls of untreated and treated Candida cells. For that, five different cells derived from different micrographs were measured in five different cell wall regions.

\subsection{Evaluation of the cytotoxic activity}

Liver tissues were rinsed in Hank's balanced salt solution containing $100 \mathrm{U} / \mathrm{mL}$ of penicillin and $100 \mu \mathrm{g} / \mathrm{mL}$ of streptomycin, and subsequently divided into $1 \times 1 \mathrm{~mm}^{3}$ explants. Some explants were placed in $25 \mathrm{~cm}^{3}$ tissue flasks, containing DMEM and supplemented with $10 \%$ fetal bovine serum, $2 \mathrm{mM}$ of non-essential amino acids, $100 \mathrm{U} / \mathrm{mL}$ of penicillin and $100 \mathrm{mg} / \mathrm{mL}$ of streptomycin, and then incubated at $37{ }^{\circ} \mathrm{C}$ with a humidified atmosphere containing $5 \% \mathrm{CO}_{2}$. This medium was replaced every 2 days, and cells cultivation continued under direct monitoring every 2-3 days using a phase contrast microscope. Prior to confluence, cells were sub-cultured and plated in 96-well plates, with a 
Table 1

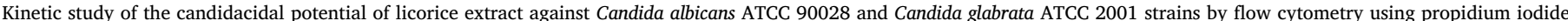
staining.

\begin{tabular}{|c|c|c|c|c|c|c|c|c|}
\hline \multirow[t]{2}{*}{ Candida species } & \multirow[t]{2}{*}{ Licorice extract $(\mathrm{mg} / \mathrm{mL})$} & \multicolumn{7}{|c|}{$\%$ of stained cells } \\
\hline & & (-) Control & $(+)$ Control & $5 \mathrm{~min}$. & $10 \mathrm{~min}$. & $15 \mathrm{~min}$. & $30 \mathrm{~min}$. & $60 \mathrm{~min}$. \\
\hline C. albicans ATCC 90028 & 1.5 & 7.7 & 83.1 & 70.0 & 73.5 & 76.8 & 78.6 & 81.3 \\
\hline C. glabrata ATCC 2001 & 1.5 & 4.8 & 88.9 & 97.2 & 97.6 & 98.4 & 98.8 & 98.9 \\
\hline
\end{tabular}

(-) Control - negative control, i.e. cells without licorice treatment; (+) Control - positive control, i.e. cells treated with ethanol $90 \%$.

(A)
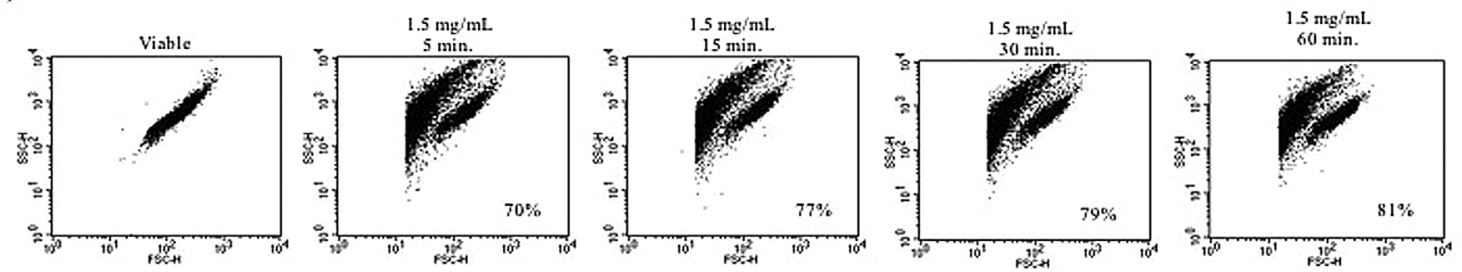

(B)
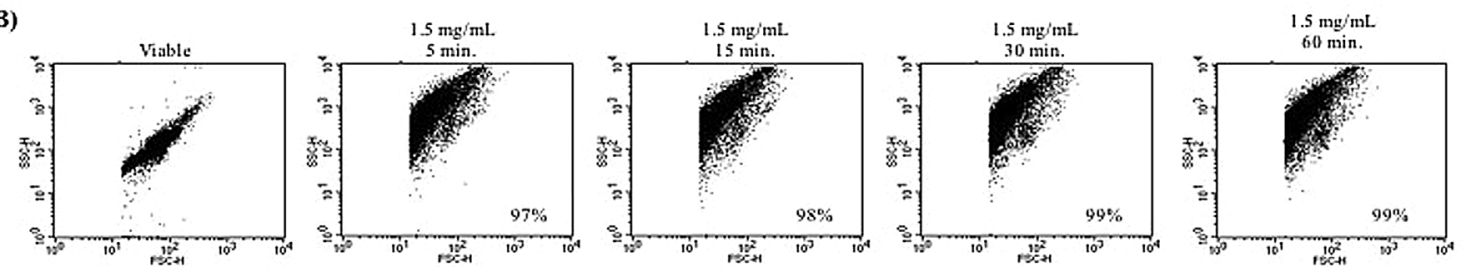

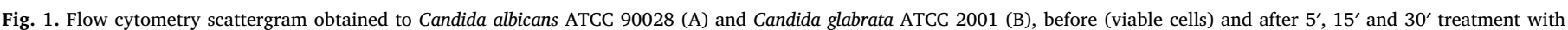
licorice methanol: water extract; \% corresponds to the $\%$ of PI stained cells.

final density of $1.0 \times 10^{4}$ cells/well and cultivated in DMEM medium, containing $10 \% \mathrm{FBS}, 100 \mathrm{U} / \mathrm{mL}$ of penicillin and $100 \mu \mathrm{g} / \mathrm{mL}$ of streptomycin (Abreu et al., 2011). Then, cells were treated for $48 \mathrm{~h}$ with the different diluted sample solutions. Three independent experiments were carried out and the results expressed in $\mathrm{GI}_{50}$ values $(\mathrm{mg} / \mathrm{mL})$, i.e. the extract concentration that inhibited $50 \%$ of net cell growth. Ellipticine was used as positive control.

\subsection{Statistical analysis}

All statistical tests were performed using IBM SPSS Statistics for Windows, version 22.0. Means were compared using Tukey's honestly significant difference (HSD) multiple comparisons test and further coupled to Welch to verify the equality of means.

\section{Results and discussion}

Candida species are responsible for several opportunistic disorders in human, which are difficult to treat mostly due to their increasing resistance to antifungals (Martins et al., 2015b). Therefore, it is very important to search and to develop efficient antifungal agents. Considering the highly effective in vitro anti-Candida activity evidenced by licorice methanol: water extract in previous experiments (Martins et al., 2016) and that the mechanism of action of this plant extract is poorly understood, it becomes essential to deepen knowledge on biocidal effect of licorice. In this sense, reference strains from $C$. albicans and $C$. glabrata species were selected to determine the effect of licorice extract on its cells by flow cytometry and transmission electron microscopy. For that, a standard concentration of licorice extract was tested based on the previous results (Martins et al., 2016) and the biocidal effect evaluated by flow cytometry (Table 1 and Fig. 1).

Flow Cytometry has been used to determine the quantitative properties of single cells, measuring cell size, cell granularity, the amounts of cell components, among other aspects in living cells, in less than one minute. With the use of fluorescent probes, flow cytometry allows to distinguish living from dead cells, to infer about membrane integrity and other indicators of microbial viability. The monitoring of transmembrane electrochemical potential and membrane damages provides rapid and feasible indications of the antimicrobial-agent-induced injury (Gokahmetoglu et al., 2003). For this reason, this technique has been markedly highlighted by several authors as a rapid and sensitive in vitro method for anti-yeasts susceptibility assessment on different Candida species isolates (Gokahmetoglu et al., 2003). This assay was based on the detection of increased permeability of Candida cells to PI, after licorice extract application.

After 5 min-licorice applications, nearly to $97 \%$ of $C$. glabrata ATCC 2001 were already PI stained (Table 1 and Fig. 1B). The effect of licorice extract on C. albicans cells (Table 1 and Fig. 1A) is relatively lower than that observed for C. glabrata cells, with a $70 \%$ of PI stained cells after $5 \mathrm{~min}$ and no pronounced alterations after 10 (73\%), 15 (77\%), $30(79 \%)$ and $60 \mathrm{~min}(81 \%)$ of licorice application. This suggests that the loss of cell integrity due to the licorice extract is not time dependent and the effects are evident immediately after application. Moreover, the fact that the cell damage to be more pronounced in $C$. glabrata cells, comparatively to $C$. albicans might be related with the different levels of complexity between Candida species, displaying $C$. albicans a more complex cellular envelope than C. glabrata species (Groot et al., 2008).

Previous experiments carried out by Gokahmetoglu et al., 2003, aiming at assessing the in vitro antifungal susceptibility of $C$. albicans to fluconazole and amphotericin B using flow cytometry observed an increasing resistance of Candida species to both anti-yeast drugs. The authors stated that were necessary at least 24-h incubation for reading microdilution assays, while to observe noticeable cell membrane damages by flow cytometry were required 4- and 2-h incubation, respectively, to fluconazole and amphotericin B (Gokahmetoglu et al., 2003). Moreover, MIC value corresponded to the lowest drug concentration used, $1 \mu \mathrm{g} / \mathrm{mL}$ and $0.25 \mu \mathrm{g} / \mathrm{mL}$ respectively, that resulted in an increase of mean channel fluorescence by 80 and $>90 \%$ of the growth control for fluconazole and amphotericin B (Gokahmetoglu 

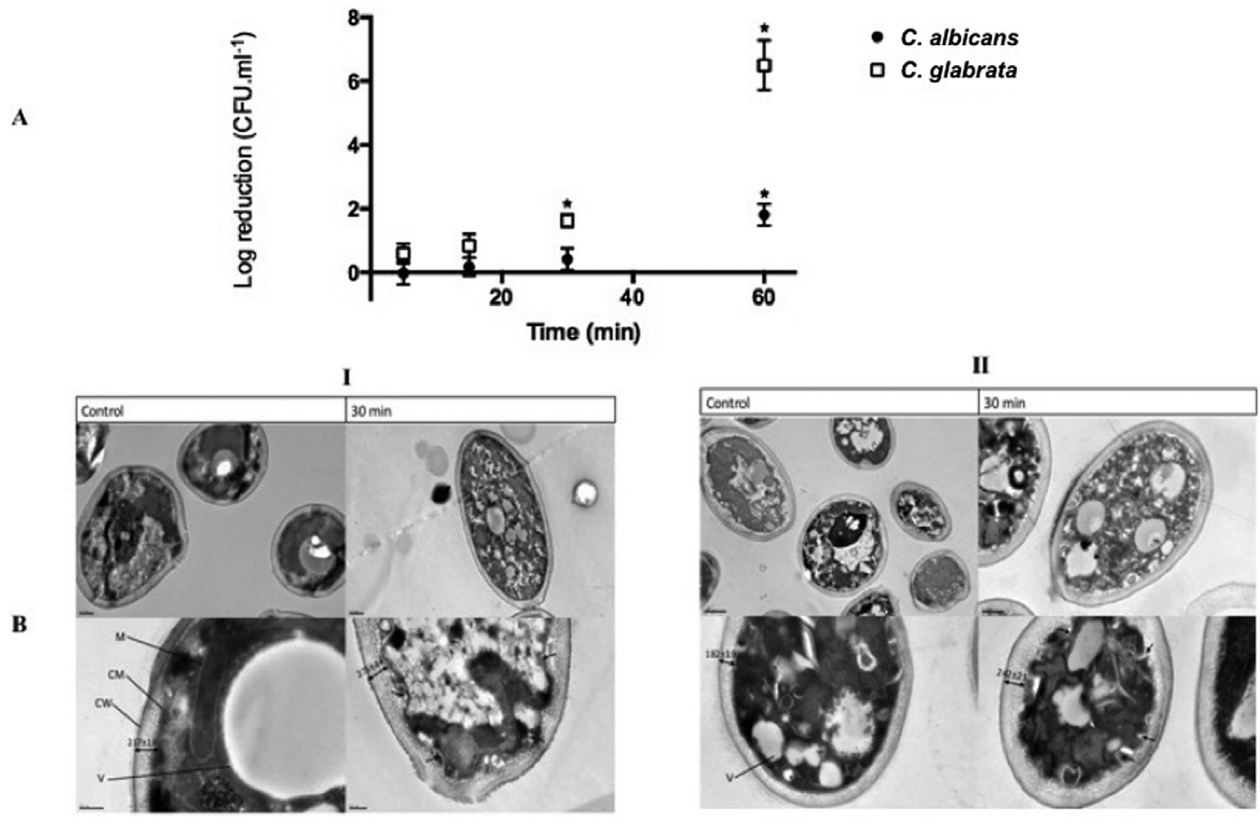

Fig. 2. Effect of licorice methanol: water extract on Candida albicans ATCC 90028 (I) and Candida glabrata ATCC 2001 (II) cells. A) Logarithm of reduction of colony forming units (CFUs) and B) Morphological cells changes evaluated by transmission electron microscopy (TEM). Error bars represent standard deviations (SD). Statistical $p$ value (represented by *) indicates concentrations that are significantly different from control. * $p<0.05$. M corresponds to mitochondria; CW corresponds to cell wall; $\mathrm{CM}$ corresponds to cellular membrane and $\mathrm{V}$ corresponds to vacuole. Arrows evidenced the presence of cell membrane invaginations. et al., 2003). Interestingly, in this study after $5 \mathrm{~min}$ of licorice application at $1.5 \mathrm{mg} / \mathrm{mL}, 70 \%$ of $C$. albicans ATCC 90028 cells presented their cell membrane compromised, while after 60 min nearly to $81 \%$ and $99 \%$ of C. albicans ATCC 90028 and C. glabrata ATCC 2001 strains were already stained with PI, respectively. These results show that this extract does not require the high exposing time that is reported for the treatments with the traditional antifungals (Martins et al., 2015c).

Based on these findings, licorice extract seems to cause serious primary cellular damages on Candida cells, once the passage of PI into the cells occurred in a fast and significant manner from the first moments, being this aspect indicative of the existence of membrane damages/lesions. In fact, after membrane destabilization, cells lack its proper homeostasis, and consequently, organic unbalance blocks its metabolic functions and cells lost functionality (Li et al., 2014; Sanglard, 2002). Notwithstanding, it is also convenient to highlight that in several cases, cells may only suffer reversible damages, and subsequently can adapt and re-acquire its functionality. Aiming to evaluate if cell membrane integrity would affect cultivability, the number of CFUs was determined. Fig. 2A shows the CFU reduction of $C$. albicans ATCC 90028 and C. glabrata ATCC 2001 strains, treated with licorice extract $(1.5 \mathrm{mg} / \mathrm{mL})$ over time. With our results, it is possible to conclude that licorice extract exerts not only reversible but also irreversible damages, leading to a significant decrease of viable cells from both Candida species populations. Moreover, it is also important to highlight that despite cell integrity loss, some Candida cells remain cultivable. The most significant reduction was observed to C. glabrata ATCC 2001, where no cultivable cells were detectable at 60 min-treatment with a reduction of approximately 7 orders of magnitude. On the other hand, a reduction of 1.8 orders of magnitude was observed, from 0 to $60 \mathrm{~min}$ of treatment of C. albicans ATCC 90028. Thus, taking it account these findings, it is possible to confirm that licorice extract presents a marked ability to exert irreversible cellular damages in both Candida strains tested.

On the other hand, and despite the scarcity of studies reporting the mechanism of action of licorice extract against Candida species, through the present study it was expected that licorice lead to microorganisms' toxicity and consequent unviability by primary cellular membrane damages. In fact, it was already reported that licorice extracts mainly acts by inhibition of enzymatic activity and consequent establishment of non-specific interactions with membrane proteins (Sher, 2009). Moreover, and not least interesting to emphasize is that Wyk et al., 2009 observed that the antifungal activity evidenced by licorice extracts against C. albicans was mainly conferred by flavonoids and isoflavonoids, which act in a synergistic manner with the other bioactive compounds presents in the samples (Jatav et al., 2011; Wyk et al., 2009), being this aspect in agreement with the results obtained in the present study.

Nevertheless, taking into account the advances reached in the last years, the number of studies assessing the type of morphological changes occurred in Candida cells still continue being scarce (Martins et al., 2015b,c). Thus, aiming to clarify the type of morphological cellular damages occurred in Candida cells, microscopic analyses using TEM were carried out, being the obtained results presented in Fig. 2B. The micrographs of the internal morphology of licorice treated C. albicans (Fig. 2I B) and C. glabrata (Fig. 2II B) cells confirms the hypothesis of the dramatic changes at $30 \mathrm{~min}$ of treatment, with the cytoplasmic disorganization coupled with notable alterations in the cytoplasmic membrane size and structure resulting in evident invaginations (see arrows). It is also important to highlight the increased of the cell membrane thickness from to $217 \pm 1.9 \mathrm{~nm}$ up to $275 \pm 4.4 \mathrm{~nm}$, and from to $182 \pm 1.9 \mathrm{~nm}$ up to $242 \pm 2.3 \mathrm{~nm}$ in case of $C$. albicans andC. glabrata respectively, after licorice application. The results suggest that the plant extract induced dysfunctions on the cell membrane and consequently, the cell lost its metabolic functions leading to viability lost as proved by the cultivability assays after 60 min (Fig. 2A).

Finally, the assessment of the cytotoxic potential of licorice extract was also performed using liver tissues. Interestingly, licorice extract exerts neither toxic effects nor morphological changes up to a concentration of $1.5 \mathrm{mg} / \mathrm{mL}$ (data not shown). Therefore, licorice seems to be an upcoming effective, efficient and safer anti-Candida drug.

\section{Conclusion}

Overall, licorice methanol: water extract exerts a prominent candidacidal effect, being this pronounced effect observable both in C. albicans and C. glabrata strains, which means that licorice extract acts efficiently in a non-selective manner.

Flow Cytometry and TEM observations revealed that this extract causes fast and irreversible damages to the cell walls of both Candida species. Moreover, it was also shown that this extract is non-toxic to liver tissues. Based on this findings licorice extract may be considered 
as promising anti-yeast agent, exerting fast and irreversible primary cellular damages both in C. glabrata and C. albicans cells, being those effects non-time-dependent.

\section{Acknowledgements}

The authors are grateful to Foundation for Science and Technology (FCT, Portugal) for N. Martins grant (SFRH/BD/87658/2012) and financial support to the research centre CIMO (strategic project PEst-OE/ AGR/UI0690/2014). This work was also supported by the Programa Operacional, Fatores de competitividade - COMPETE and by national funds through FCT - Fundação para a Ciência e a Tecnologia on the scope of the projects FCT PTDC/SAU-MIC/119069/2010, RECI/EBBEBI/0179/2012 and PEst-OE/EQB/LA0023/2013. The authors thank the Project "BioHealth - Biotechnology and Bioengineering approaches to improve health quality", Ref. NORTE-07-0124-FEDER-000027, cofunded by the Programa Operacional Regional do Norte (ON.2-O Novo Norte), QREN, FEDER.

\section{References}

Abreu, R.M.V., Ferreira, I.C.F.R., Calhelha, R.C., Lima, R.T., Vasconcelos, M.H., Adega, F., Chaves, R., Queiroz, M.J.R.P., 2011. Anti-hepatocellular carcinoma activity using human HepG2 cells and hepatotoxicity of 6-substituted methyl 3- aminothieno [3,2b] pyridine-2-carboxylate derivatives: in vitro evaluation, cell cycle analysis and QSAR studies. Eur. J. Med. Chem. 46, 5800-5806.

Faria, N.C.G., Kim, J.H., Gonçalves, L.A.P., Martins, M., de, L., Chan, K.L., Campbell, B.C., 2011. Enhanced activity of antifungal drugs using natural phenolics against yeast strains of Candida and Cryptococcus. Lett. Appl. Microbiol. 52, 506-513. http://dx. doi.org/10.1111/j.1472-765X.2011.03032.x.

Gokahmetoglu, S., Koc, A.N., Patiroglu, T., 2003. Antifungal susceptibility testing of Candida albicans by flow cytometry. Mycoses 46, 289-293.

Groot, P.W.J., Kraneveld, E.A., Yin, Q.Y., Dekker, H.L., Groß, U., Crielaard, W., Koster, C.G., Bader, O., Klis, F.M., Weig, M., 2008. The cell wall of the human pathogen Candida glabrata: differential incorporation of novel adhesin-like wall proteins. Eukaryot. Cell 7, 1951-1964. http://dx.doi.org/10.1128/EC.00284-08.

Jatav, V.S., Singh, S.K., Khatri, P., Sharma, A.K., 2011. Recent pharmacological trends of Glycyrrhiza. Int. J. Pharm. Res. 1, 170-185.
Jiang, Z., Gu, J., Wang, C., Wang, S., Liu, N., Jiang, Y., Dong, G., Wang, Y., Liu, Y., Yao, J., Miao, Z., Zhang, W., Sheng, C., 2014. Design, synthesis and antifungal activity of novel triazole derivatives containing substituted 1,2,3-triazole-piperdine side chains. Eur. J. Med. Chem. 82, 490-497. http://dx.doi.org/10.1016/j.ejmech.2014.05.079.

Kanafani, Z.A., Perfect, J.R., 2008. Resistance to antifungal agents: mechanisms and clinical impact. Clin. Infect. Dis. Antimicrob. Resist. 46, 120-128. http://dx.doi.org/ 10.1086/524071.

Li, A., Li, S., Zhang, Y., Xu, X., Chen, Y., Li, H., 2014. Resources and biological activities of natural polyphenols. Nutrients 6, 6020-6047. http://dx.doi.org/10.3390/ nu6126020.

Lopes, G., Pinto, E., Andrade, P.B., Valentão, P., 2013. Antifungal activity of phlorotannins against dermatophytes and yeasts: approaches to the mechanism of action and influence on Candida albicans virulence factor. PLoS One 8, 1-10. http://dx.doi org/10.1371/journal.pone.0072203.

Martins, N., Ferreira, I.C.F.R., Barros, L., Silva, S., Henriques, M., 2014. Candidiasis: predisposing factors, prevention, diagnosis and alternative treatment. Mycopathologia 177, 223-240. http://dx.doi.org/10.1007/s11046-014-9749-1.

Martins, N., Barros, L., Dueñas, M., Santos-Buelga, C., Ferreira, I.C.F.R., 2015a. Characterization of phenolic compounds and antioxidant properties of Glycyrrhiza glabra L. rhizomes and roots. RSC Adv. 5, 26991-26997. http://dx.doi.org/10.1039/ C5RA03963K.

Martins, N., Barros, L., Henriques, M., Silva, S., Ferreira, I.C.F.R., 2015b. Activity of phenolic compounds from plant origin against Candida species. Ind. Crops Prod. 74, 648-670. http://dx.doi.org/10.1016/j.indcrop.2015.05.067.

Martins, N., Barros, L., Henriques, M., Silva, S., Ferreira, I.C.F.R., 2015c. In vivo antiCandida activity of phenolic extracts and compounds: future perspectives focusing on effective clinical interventions. Biomed Res. Int. 2015, 1-14. http://dx.doi.org/10. $1155 / 2015 / 247382$.

Martins, N., Ferreira, I.C.F.R., Henriques, M., Silva, S., 2016. In vitro anti-Candida activity of Glycyrrhiza glabra L. Ind. Crop. Prod. 83, 81-85. http://dx.doi.org/10.1016/j. indcrop.2015.12.029.

Perlin, D.S., 2009. Resistance to echinocandin-class antifungal drugs. Drug Resist. Updat. 10, 121-130. http://dx.doi.org/10.1016/j.drup.2007.04.002. Resistance.

Rasband, W.S., n.d. ImageJ [WWW Document]. U. S. Natl. Institutes Heal. URL http:// imagej.nih.gov/ij/.

Sanglard, D., Odds, F.C., 2002. Reviews resistance of Candida species to antifungal agents: molecular mechanisms and clinical consequences. Lancet Infect. Dis. 2, 73-85.

Sanglard, D., 2002. Resistance of human fungal pathogens to antifungal drugs. Curr. Opin. Microbiol. 5, 379-385.

Sher, A., 2009. Antimicrobial activity of natural products from medicinal plants. Gomal J. Med. Sci. 7, 72-78.

Wyk, C., Van Botha, F.S., Steenkamp, V., 2009. In vitro antimicrobial activity of medicinal plants against oral Candida albicans isolates. Int. J. Biomed. Pharm. Sci. 3, 26-30. 